\title{
A EDUCAÇÃO AMBIENTAL E O ENSINO JURÍDICO: EVIDENCIANDO LIAMES
}

\section{Heron Gordilho ${ }^{1}$ \\ Fernando de Azevedo Alves Brito ${ }^{2}$}

Resumo: Este artigo tem por objetivo analisar os liames (jurídicos e teóricos) existentes entre a Educação Ambiental e o Ensino Jurídico. Para tanto, considera os resultados de uma pesquisa (estudo de caso) realizada por Brito (2013). Os resultados da pesquisa mencionada apontaram para a inadequação da implementação da Educação Ambiental no Curso de Direito, em prejuízo das exigências legais e das perspectivas teóricas adotadas. Diante dessa realidade, este trabalho busca evidenciar liames existentes entre os dois campos do saber, em prol da formação de cidadãos ambientais nas Graduações de Direito. A opção metodológica foi pela revisão bibliográfica, recorrendo-se à análise documental.

Palavras-chave: Educação Ambiental, Ensino Jurídico, Cidadania Ambiental, Percepção Ambiental, Graduação em Direito.

\section{ENVIRONMENTAL EDUCATION AND LEGAL TEACHING: EVIDENCING ENTAILMENT}

\begin{abstract}
This paper is to analyze the entailment (legal and theoretical) between environmental education and legal teaching. In order to do so, it considers the results of a research (case study) carried out by Brito (2013). The results of the mentioned research pointed to the inadequacy of the implementation of environmental education in the Law Course, to the detriment of legal requirements and theoretical perspectives adopted. Towards this reality, this work seeks to highlight existing entailment between these two fields of knowledge, in favor of the environmental citizens' formation in Law Graduations. The methodological option was through bibliographical review, resorting to documentary analysis.
\end{abstract}

Keywords: Environmental Education, Legal Teaching, Enviroonmental Citizenship, Environmental Perception, Law Graduation.

\footnotetext{
1 Pós-Doutor em Direito Ambiental pela Pace University (EUA). Doutor em Direito pela Universidade Federal de Pernambuco (UFPE). Mestre em Direito pela Universidade Federal da Bahia (UFBA). Mestre em Sociologia pela UFBA. Coordenador do Programa de Pós-Graduação Stricto Sensu em Direito da UFBA. Professor da UFBA e da Universidade Católica de Salvador (UCSAL). Membro da World Academy of Art \& Science (WAAS). Promotor de Justiça Ambiental (MP/BA). Email: heron@ufba.br. Lattes: http://lattes.cnpq.br/9247033382457379. 2 Professor EBTT de Direito do Instituto Federal de Educação, Ciência e Tecnologia da Bahia (IFBA), Campus Vitória da Conquista. Aluno especial do Doutorado em Direito da Universidade Federal da Bahia (UFBA). Mestre em Ciências Ambientais pela Universidade Estadual do Sudoeste da Bahia (UESB). Membro da Associação de Professores de Direito Ambiental do Brasil (APRODAB). E-mail: fernando.brito@ifba.edu.br. Lattes: http://lattes.cnpq.br/4135642428062326.
}

Rev. de Direito Ambiental e Socioambientalismo | e-ISSN: 2525-9628 | Maranhão | v. 3 | n. 2 | p. 22 - 41 | Jul/Dez. 2017 


\section{INTRODUÇÃO}

Se a história da Educação Ambiental no mundo e no Brasil, do ponto de vista teórico e normativo, deu-se lado a lado à história do próprio movimento ambientalista, faz-se necessário reconhecer-se que a crise ambiental na contemporaneidade foi o pano de fundo desse cenário (BRASIL, 1988).

A Educação Ambiental, nesse panorama, apresentou-se como um instrumento hábil ao gradativo estímulo de reversão da crise ambiental provocada pelos próprios seres humanos. Não foi por outro motivo que os tratados internacionais, as constituições nacionais e normas infraconstitucionais de diversos países passaram, gradativamente, a regular o tema, assim como o próprio Direito Ambiental. Essas normas objetivaram estimular a formação do cidadão ambiental, até mesmo porque o art. 225, caput, da Constituição Federal de 1988, destinou não apenas ao Poder Público, mas à coletividade, o dever de proteger e preservar o meio ambiente ecologicamente equilibrado para as presentes e futuras gerações. Com isso e diante do art. 225, $\S 1^{\circ}$, VI, a Educação Ambiental, em dimensões formal e não-formal, tornou-se ainda mais relevante no Brasil (BRASIL, 1988).

É importante compreender, no entanto, que o Ensino Jurídico, no decorrer da história brasileira, não se manteve imutável, até mesmo porque a sua mutabilidade seria oriunda da natural evolução do próprio Direito, enquanto campo do saber, bem como da paulatina alteração das normas brasileiras que lhe regulavam. O certo é que, em termos gerais, entre o Ensino Jurídico originariamente europeu, em especial o português, destinado a alguns poucos abastados, até a criação da Resolução CNE/CES nº 9/2004, instituidora das Diretrizes Curriculares Nacionais do Curso de Graduação em Direito, o Ensino Jurídico brasileiro passou por fases marcantes, que envolveram de normas educacionais rígidas e taxativas (currículo pleno) para normas educacionais parcialmente rígidas, asseguradoras da autonomia universitária na composição do currículo (currículo mínimo) (BRITO, F. 2013).

Indiferente a esse processo particular de evolução do Ensino Jurídico, as normas vigentes sobre Educação Ambiental (internacionais, nacionais e, até mesmo, estaduais) estabelecem a necessidade de sua implementação, de modo transversal e inter/transdisciplinar, em todos os níveis de ensino, na educação formal e não-formal, em benefício de todos - o que inclui os Cursos de Graduação em Direito.

Tendo em vista essa realidade, o presente artigo guiou-se pela seguinte questão: quais os liames (jurídicos e teóricos) existentes entre a Educação Ambiental e o Ensino Jurídico? 
Tendo, ainda, como objetivo geral "analisar os liames (jurídicos e teóricos) existentes entre a Educação Ambiental e o Ensino Jurídico".

O presente artigo também guiou-se pelos seguintes objetivos específicos: (a) investigar a Educação Ambiental, de modo a evidenciar os seus fundamentos normativos e teóricos; (b) investigar o Ensino Jurídico, de modo a evidenciar, os seus fundamentos normativos e teóricos; (c) analisar, panoramicamente, a distinção entre a disciplina de Direito Ambiental e a Educação Ambiental; (d) evidenciar liames existentes entre a Educação Ambiental e o Ensino Jurídico, tendo como referência a pesquisa desenvolvida por F. Brito (2013).

A relevância do presente artigo é evidente, uma vez que, mesmo diante do arcabouço normativo vigente sobre a Educação Ambiental, é sabido que a adoção de práticas transversais e inter/transdisciplinares no Ensino Jurídico, sofre, muitas vezes, resistência por parte dos professores, coordenadores e diretores de Cursos de Direito, uma vez que esses profissionais se formaram no mesmo sistema positivista, tecnicista e cartesiano, que deveriam combater. Por corolário, apresentam-se relutantes em acatar a comunicação do Direito com outros campos.

No mais, a opção metodológica foi pela revisão bibliográfica, recorrendo, quando oportuno, à análise documental.

\section{EDUCAÇÃO AMBIENTAL: ASPECTOS NORMATIVOS E TEÓRICOS}

\subsection{Fundamentos Históricos e Marco Normativo}

Se a primeira referência histórica à expressão "Educação Ambiental” (environmental education) costuma ser associada à Conferência de Educação da Universidade de Keele, feita na Grã-Bretanha (1965), afirma-se que tomou contornos mais definidos com a Conferência de Estocolmo, realizada na Suécia (1972). Nessa oportunidade, foi firmada como $19^{\circ}$ princípio da Declaração de mesmo nome (BRITO, F., 2013), abrangendo: (a) a indispensabilidade do trabalho da educação ambiental; (b) a destinação às gerações jovens e aos adultos, com ênfase nas populações menos privilegiadas; (c) a formação de uma opinião pública bem informada dos indivíduos, das empresas e das comunidades; e (d) o senso de responsabilidade com a proteção e com o melhoramento do meio ambiente, na dimensão humana (ONU, 1972).

A partir da Carta de Belgrado, elaborada na antiga Iugoslávia (1975), ampliaram-se as disposições acerca do tema, de maneira a abarcar metas nacionais, objetivos, princípios e diretrizes programáticas com a finalidade de viabilizar-se parâmetros internacionais para a

Rev. de Direito Ambiental e Socioambientalismo | e-ISSN: 2525-9628 | Maranhão | v. 3 | n. 2 | p. 22 - 41 | Jul/Dez. 2017 
Educação Ambiental e, ainda, observar a Recomendação no 96 da Conferência sobre o Meio Ambiente Humano de Estocolmo (BRITO, F., 2013).

O referido documento, ao definir o seu público alvo, foi o primeiro a apontar que a Educação Ambiental aplicar-se-ia tanto na educação formal como na educação não-formal, em benefício do público em geral. Para tanto, estabeleceu que a sua meta era formar a população (consciente e preocupada) com o meio ambiente e com os problemas associados. Qualidades como conhecimento, aptidão, atitude, motivação e compromisso para trabalhar em prol da solução dos problemas existentes e da prevenção de outros novos agregar-se-iam à meta da Educação Ambiental, assim como a capacidade cidadã de avaliação das medidas e dos programas de educação ambiental agregar-se-ia aos seus objetivos (ONU, 1975).

A tendência de ampliação dos dispositivos sobre o tema no Direito Internacional manteve-se com a Conferência de Tbilisi, ocorrida na Geórgia (1977). Nessa oportunidade, estabeleceram-se vários princípios da Educação Ambiental, a exemplo: da interdisciplinaridade, da crítica e da finalidade transformadora (BRITO, F., 2013). O Tratado de Tbilisi ainda estabeleceu finalidades e categorias de objetivos, bem como reconheceu um público-alvo mais extenso e diversificado para as práticas da Educação Ambiental, envolvendo todos os grupos de idades e de categorias profissionais, jovens e adultos não-especializados e grupos sociais específicos, tais quais técnicos e cientistas (ONU, 1977).

A Educação Ambiental teve relevante abordagem na Conferência sobre o Meio Ambiente e Desenvolvimento (UNCED, 1992), desenvolvida no Rio de Janeiro (1992). Como resultado dessa conferência foi elaborado o Tratado de Educação Ambiental para Sociedades Sustentáveis, que reconheceu 16 princípios em prol da "educação para sociedades sustentáveis e responsabilidade global”. Deles, destacam-se os princípios 2 e 3, galgados no pensamento crítico e inovador para a transformação e na construção da sociedade e, ainda, no propósito de formar cidadãos com consciência local e planetária (BRITO, F., 2013; ONU, 1992).

Nesse panorama, observa-se que o Direito Ambiental Internacional colaborou, de maneira significativa, para o desenvolvimento teórico e prático, por vezes metodológico, da educação ambiental, dentro e fora do Brasil. Essa é a razão da legislação ambiental brasileira, assim como os conceitos doutrinários desenvolvidos sobre o tema, harmonizarem-se com o teor dos referidos tratados internacionais. Tudo isso a favor da mudança de comportamentos dos indivíduos da espécie humana a favor da tutela ambiental. Criticidade, participação e ética são condutas esperadas nessa mudança, o que exige uma educação ambiental substancial, para além de um mero “adestramento” ecológico do público-alvo (BRITO, F., 2013). 
Tendo como parâmetro a legislação brasileira, pode-se afirmar que a Educação Ambiental foi regulada por múltiplas normas. Nesse sentido, a Lei $\mathrm{n}^{\circ} 6.938 / 1981$, com toda a sua relevância, concedeu-lhe o status de princípio da Política Nacional do Meio Ambiente (PNMA), nas seguintes condições para a sua implementação: (a) ser obrigatória; (b) ser realizada em todos níveis de ensino, abrangendo de igual modo a educação comunitária; e (c) objetivar capacitar para a participação ativa na tutela do meio ambiente (BRASIL, 1981).

Um pouco mais jovem, a Constituição Federal de 1988 seguiu a tendência da Lei $n^{\circ}$ 6.938/1981, ao incumbir o Poder Público de promover a Educação Ambiental em todos os níveis de ensino, bem como de promover a conscientização pública para a preservação do meio ambiente ecologicamente equilibrado (art. 225, $\S 1^{\circ}$, VI) (BRASIL, 1988).

Com a Lei no 9.795/1999, que instituiu a Política Nacional de Educação Ambiental (PNEA), o tema teve a sua mais extensa e complexa regulação, nem por isso deixando de demonstrar clara influência dos tratados internacionais já abordados. Entre outras questões, apresentou a definição de educação ambiental:

Os processos por meio dos quais o indivíduo e a coletividade constroem valores sociais, conhecimentos, habilidades, atitudes e competências voltadas para a conservação do meio ambiente, bem de uso comum do povo, essencial à sadia qualidade de vida e sua sustentabilidade (BRASIL, 1999, p. 1).

Coube a Educação Ambiental, ainda: (a) ser reconhecida como um direito de todos (art. $3^{\circ}$ ); (b) ser considerada um componente essencial e permanente da educação nacional (art. $2^{\circ}$, $1^{a}$ parte); e (c) ter a sua inclusão, de maneira articulada, em todos os níveis/modalidades do processo educativo formal e não-formal (art. 2º $2^{\text {a }}$ parte) (BRASIL, 1999; BRITO, F., 2013).

Se o art. 4º da mencionada lei estabeleceu os princípios básicos da Educação Ambiental, deve-se destacar o primeiro, uma vez que a destina enfoque humanista, holístico, democrático e participativo (BRASIL, 1999).

Além das normas jurídicas já expostas, diversas outras internalizaram a matéria, o que evidencia que o Brasil privilegiou o tema e assumiu, em dimensão estatal, o compromisso de sua implementação, objetivando formar o indivíduo-sujeito para o exercício da cidadania ambiental. Tudo isso em prol da proteção do meio ambiente ecologicamente equilibrado para as presentes e futuras gerações, nos termos do art. 225, caput, da Constituição Federal de 1988. Desse modo, também normatizaram a Educação Ambiental: (a) a Lei n 9.394/1996, no art. 32, II; (b) a Lei $n^{\circ} 9.985 / 2000$, no art. $5^{\circ}$, IV; (c) o Decreto $n^{\circ} 4.281 / 2002$, que regulamenta a Lei $n^{\circ}$ 9.795/1999 (c) o Decreto $n^{\circ} 4.339 / 2002$, nos itens 2, XIV, e 9, VI; (d) a Lei no 12.187/2009, 
nos arts. $5^{\circ}$, XII, e $6^{\circ}$, XIV; e (e) a Lei no 12.305/2010, nos arts. $5^{\circ}$, art. $8^{\circ}$, VIII, e 19, IX ${ }^{3}$.

Sintetizando as normas jurídicas apontadas, pode-se afirmar que a Educação Ambiental deve ser realizada, de forma transversal e inter/transdisciplinar, em todos os níveis de ensino, tanto na educação formal como na educação não-formal, objetivando formar, conscientizar e sensibilizar o cidadão ambiental (BRASIL, 1999). É necessário, em caráter complementar, admitir que, ao estendê-la à modalidade não-formal, reconheceu-se a necessidade de sua concretização para além dos muros das instituições tradicionais de ensino. Assim, passa a ser exigível em todo o exercício educacional em nível comunitário, ainda que não-escolar, em benefício de todos, o que inclui atividades educativas desenvolvidas por pessoas públicas ou privadas (BRITO, F.; BRITO, Á., 2017).

\subsection{Fundamentos Teóricos}

A doutrina, via de regra, costuma efetivar críticas severas às tentativas reducionistas de conceituação da Educação Ambiental. Nesse panorama, entende-se que não deve ser reduzida a uma mera dimensão ecologista, naturalista, conservadora. Isto porque perderia a sua legitimidade social e coerência, pois as questões socioambientais, para as quais busca solução, situam-se no âmbito sociopolítico, em campos como a superação da pobreza e a participação cidadã. Isso permite concluir a favor da impossibilidade de que "assepsias cientificistas" (ecológicas, biológicas ou tecnológicas) resolvam os problemas ambientais (LUZZI, 2005).

Esse entendimento, sem embargo, exige que a Educação Ambiental considere uma dimensão ambientalista propriamente dita (complexa, interdisciplinar e integrada), que abarque o ser humano e as questões humanísticas. Isso deve se estender à sua teoria e prática (LUZZI, 2005; BRITO, F., 2013). Deve-se, ademais, combater a projeção do pensamento reducionista na Educação Ambiental; a sua limitação a uma mera conscientização geral dos sujeitos, que costuma estar relacionada à fragmentação do saber ambiental (LEFF, 2001).

Há quem entenda a educação como uma espécie de subsistema social destituído de vida autônoma, que se subordina a um contexto social e histórico maior. Nessa perspectiva, objetivaria identificar as forças políticas, culturais e filosóficas que a influenciam (LIMA, 2008). A Educação Ambiental, portanto, ultrapassa as dimensões de um mero instrumento de formação/instrução ecológica dos indivíduos, até mesmo pelo fato de envolver nuances

\footnotetext{
${ }^{3}$ Pode-se, outrossim, fazer menção às Resoluções do MEC CNE/CP n 1 e no 2/2012, que estabelecem, respectivamente, as Diretrizes Curriculares Nacionais para a Educação em Direitos Humanos e às Diretrizes Curriculares Nacionais para a Educação Ambiental. Ambas abordam aspectos relevantes da educação ambiental para a educação formal.
}

Rev. de Direito Ambiental e Socioambientalismo | e-ISSN: 2525-9628 | Maranhão | v. 3 | n. 2 | p. 22 - 41 | Jul/Dez. 2017 
múltiplas e complexidade inata. Daí porque a necessidade de preparar-se os sujeitos para o exercício de uma postura crítica, ética e participativa na tutela ambiental (BRITO, F., 2013).

Apresenta-se coerente o conceito de Educação Ambiental como "uma práxis educativa e social que tem por finalidade a construção de valores, conceitos, habilidades e atitudes que possibilitem o entendimento da realidade da vida e a atuação lúcida e responsável de atores sociais individuais e coletivos no ambiente" (LOUREIRO, 2008, p. 69). Visão que, aliás, harmoniza-se com a definição prevista no art. $3^{\circ}$ da Resolução CNE/CP n n $^{\circ}$ 2012: "visa à construção de conhecimentos, ao desenvolvimento de habilidades, atitudes e valores sociais, ao cuidado com a comunidade de vida, a justiça e a equidade socioambiental, e a proteção do meio ambiente natural e construído" (BRASIL, 2012, p. 1). Não há dúvidas, portanto, de que o cidadão ambiental deve nutrir-se desses valores, estar apto ao exercício dessas habilidades e apresentar essas atitudes em sociedade (BRITO, F., 2013).

Diante disso, a Educação Ambiental, como práxis educativa e social, exibe uma relação entre teoria e prática, na qual se desenvolve o entendimento do ser humano e do meio social em que vive, bem como do espaço no qual a educação objetiva formar o cidadão e a sua condição humana (BRITO, F.; BRITO, Á., 2017). Por essa razão, deve-se entendê-la como um aparato essencial a um novo padrão civilizacional e societário, fundado em uma outra ética sociedadenatureza, da mesma forma que um fator estratégico na formação da criticidade em face das relações sociais e produtivas LOUREIRO (2008).

Considerando a multiplicidade de normas jurídicas que regulam o tema (nos níveis internacional, federal, estadual e, até, municipal), o conceito de Educação Ambiental, abordado pela doutrina - como não poderia deixar de ser -, vê-se bastante influenciado pelo conteúdo normativo específico (BRITO, F.; BRITO, Á., 2017). Assim, se as normas jurídicas vigentes atribuem à Educação Ambiental o papel de formar o indivíduo-sujeito para o exercício da cidadania ambiental - entenda-se por isso, inclusive, ser participativo nas instâncias governamentais dedicadas à esfera ambiental -, os conceitos apontados pelos autores tendem, da mesma maneira, a seguir essa perspectiva (BRITO, F., 2013).

A influência normativa na produção teórica da Educação Ambiental dá-se, igualmente, quanto à metodologia de ensino aplicável (transversal e inter/transdisciplinar). Sendo a educação interdisciplinar um processo de formação de mentalidades/habilidades que fomentam a apreensão da realidade complexa, a Educação Ambiental deve agregar não só princípios e valores ambientais promovidos por uma pedagogia do ambiente, mas se enriquecer como uma pedagogia da complexidade, que induza os educandos: (a) a uma perspectiva de 
multicausalidade e de interrelações dos distintos processos que compõem o seu mundo de vida nas diversas etapas de desenvolvimento psicogenético; e (b) ao desenvolvimento de um pensamento crítico/criativo fundado em novas capacidades cognitivas (LEFF, 2001).

Deve, enfim, incidir na formação política do cidadão para o socioambiental, o que abrange, entre outras nuances, a fiscalização do Poder Público e a proteção do meio ambiente ecologicamente equilibrado (art. 225, caput, da CF/1988). A formação ecológica dos indivíduos e o estímulo ao exercício da cidadania ambiental, abrange o fomento à ética, à criatividade, à cooperação e à participação, à integração de conhecimentos teóricos com os práticos, dos científicos com os tradicionais, à busca da sustentabilidade ambiental e à consolidação de condições sociais, econômicas, políticas, culturais e humanas, mais justas (BRITO, F. 2013).

\section{ENSINO JURÍDICO E EDUCAÇÃO AMBIENTAL: ENTRELAÇANDO TEMAS}

\subsection{Considerações iniciais}

Não nos cabe neste capítulo versar sobre a gênese e a evolução do Ensino Jurídico brasileiro. Isto porque, não obstante a perspectiva histórica seja relevante - que abrangeu um salto significativo de uma formação jurídica de brasileiros abastados em solo europeu, principalmente na Faculdade de Direito de Coimbra, para a sanção da Carta de Lei de 11 de agosto de 1827, que criou dois cursos de ciências jurídicas e sociais nas cidades de São Paulo e Olinda (BRASIL, 1827; FORNARI, 2007) -, este artigo busca realizar um estudo direcionado à legislação vigente, para evidenciar liames entre o Ensino Jurídico e a Educação Ambiental.

É importante compreender, no entanto, que o Ensino Jurídico no Brasil, no decorrer da história, não se manteve na condição de estabilidade/imutabilidade. Essa mutabilidade é oriunda da natural evolução teórica e técnica do próprio Direito, enquanto campo do saber, e, ainda, da paulatina alteração das normas brasileiras regulamentadoras do tema. Nesse ínterim, passou-se de um Ensino Jurídico originariamente português para um ensino jurídico brasileiro e, neste, passou-se de normas educacionais rígidas e taxativas (currículo pleno) para normas educacionais parcialmente rígidas, que passaram a assegurar a autonomia universitária na composição do currículo (currículo mínimo). Todo esse processo culminou na Resolução CNE/CES n ${ }^{\circ}$ 9/2004, instituidora das Diretrizes Curriculares Nacionais do Curso de Graduação em Direito (BRITO, F., 2013). 
As discussões, aliás, no presente, estão avançadas para a reformulação da Resolução CNE/CES n 9/2004 e a consequente criação de novas Diretrizes Curriculares Nacionais para os Cursos de Graduação em Direito. Essa realidade reafirma a mutabilidade do Ensino Jurídico e a sua constante evolução.

\subsection{Ensino jurídico: entre o direito ambiental e a educação ambiental}

Como já afirmado, a evolução das normas educacionais regulamentadoras dos cursos de graduação em Direito no Brasil culminou com a elaboração da Resolução CNE/CES n ${ }^{\circ}$ 9/2004, que estabeleceu as Diretrizes Curriculares Nacionais do Curso de Graduação em Direito. Destaca-se que no ano de criação desta Resolução, as normas jurídicas ambientais (internacionais, federais e estaduais) aplicáveis à Educação Ambiental já estavam, pois, consolidadas. Assim, se as referidas Diretrizes não previram expressamente a exigência de inclusão da Educação Ambiental nos Cursos de Direito, não significa que lhe fossem avessas. Até mesmo porque o arcabouço normativo vigente, em sede de Educação Ambiental, a exemplo do art. 225, § $1^{\circ}$, VI da Constituição Federal de 1988, exige-a em todos os níveis de ensino, na educação formal e não-formal (BRITO, F., 2013).

Não é à toa que as Resoluções CNE/CP n ${ }^{\circ} 1$ e no 2/2012 do MEC exigem a inclusão da Educação Ambiental no ensino superior. A primeira delas, apesar de não versar expressamente - tal qual a segunda - sobre Educação Ambiental, mas sobre o ensino de Direitos Humanos, também envolve a difusão das temáticas ambientais no ensino superior e, portanto, nos Cursos de Graduação em Direito (BRITO, F., 2013).

A própria Resolução CNE/CES nº 9/2004 revela compatibilidade do Ensino Jurídico com a Educação Ambiental. Percebe-se essa realidade no seu art. $2^{\circ}$, no $\S 1^{\circ}$, quando estabelece como elementos estruturais do Projeto Pedagógico do Curso de Direito (PPC): (a) a necessidade de contextualização da concepção e dos objetivos gerais do Curso às suas inserções institucional, política, geográfica e social; (b) formas de realização da interdisciplinaridade; (c) modos de integração entre teoria e prática; (d) incentivos à pesquisa e à extensão, como prolongamento da atividade de ensino e como instrumento da iniciação científica (BRASIL, 2004; BRITO, 2013).

Nesse sentido, destaca-se que as Diretrizes Curriculares Nacionais do Curso de Graduação em Direito estabelecem um rol exemplificativo de elementos estruturais a serem implementados, que pode, portanto, ser considerada como integrante da Educação Ambiental, 
cuja implementação no ensino superior é exigida pela legislação brasileira vigente. Nesses termos, ainda que não seja expressamente referida na Resolução CNE/CES nº 9/2004, a Educação Ambiental é uma exigência estrutural nos Cursos de Graduação em Direito e deve integrar o PPC do Curso, por meio de suas concepções e objetivos gerais, formas de realização da interdisciplinaridade, modos de integração entre teoria e prática e, entre outros, incentivo à pesquisa e à extensão (BRITO, F., 2013).

Tudo isso deve mirar a formação do perfil do aluno estabelecido no art. $3^{\circ}$ da Resolução e, nesse contexto, é inevitável associar a exigência de uma formação geral, humanística e axiológica, de uma capacidade de análise, de um domínio de conceito no perfil do graduando, com o desempenho adequado de sua formação do estudante enquanto indivíduo-sujeito ambiental, isto é, enquanto cidadão ambiental. Desse cenário, extrai-se a necessidade de implementação da Educação Ambiental nos Cursos de Direito. Ademais, a reflexão sobre aspectos ambientais, dos mais basilares aos mais complexos, é fundamental para o estímulo da postura reflexiva e da visão crítica, nos moldes do art. $3^{\text {o; }}$; afinal, fomenta a aprendizagem autônoma e dinâmica a favor do exercício da cidadania (BRITO, F., 2013).

Há um vínculo natural entre a formação humanística do bacharel em Direito e a compreensão de questões ambientais. A exemplo disso, no século XXI, os chamados conflitos de massa - em torno de questões agrárias, ambientais, urbanísticas, de cidadania e do consumidor -, exigem soluções adequadas. Isso impõe, à cultura jurídica, a necessidade de proporcionar uma formação interdisciplinar e humanística dos bacharéis em Direito, por meio de uma "ciência verdadeiramente capaz de compreender os novos rumos da realidade", ao buscar, entre outros aspectos, solução para os conflitos distributivos e "a construção de uma sociedade assentada em valores autênticos" (MACHADO, 2009).

Nesse contexto, seria necessária para a compreensão dessa realidade um trabalho interdisciplinar, envolvendo a análise de fenômenos como problemas oriundos: (a) da globalização; (b) dos direitos humanos; (c) do acesso à justiça; (d) do meio ambiente; (e) da questão agrária; (f) do urbanismo; (g) da bioética; (h) da democracia; e, entre outros, (i) do papel do Estado. Essas análises exigem a adoção de uma metodologia educacional inter/transdisciplinar, capaz de viabilizar a compreensão do fenômeno jurídico em sua totalidade histórica, em prol da superação de suas contradições e da viabilização de realidades jurídicas eticamente sustentáveis (MACHADO, 2009). Essa metodologia é compatível com aquelas estabelecidas pela legislação vigente para a Educação Ambiental.

Rev. de Direito Ambiental e Socioambientalismo | e-ISSN: 2525-9628 | Maranhão | v. 3 | n. 2 | p. 22 - 41 | Jul/Dez. 2017 
Nesse panorama, fica evidente que a ausência de referência direta/expressa à Educação Ambiental na Resolução CNE/CES n 9/2004, não afasta a necessidade de sua implementação nos Cursos de Direito, haja vista ser indispensável à formação humanística do bacharel em Direito, o que, do mesmo modo, exige a adoção de metodologia transversal e inter/transdisciplinar. Isso é essencial, inclusive, para que a teoria do direito adéque-se, na atualidade, ao fenômeno jurídico, abrindo-se ao universo das humanidades, ao mesmo tempo que amplia o seu universo cognitivo, como ciência jurídica (BRITO, 2013; KOZICKI, 2007).

Considerando o art. $2^{\circ}$, IV, da Resolução, é importante reconhecer que somente um pensamento verdadeiramente interdisciplinar, por afastar-se da análise tecnicista do ordenamento jurídico vigente, torna factível a transformação da realidade (KOZICKI, 2007). E esse pensamento interdisciplinar exige, igualmente, a abordagem ambiental, ainda que, na norma específica não se faça menção expressa à educação ambiental ou a quaisquer outros conteúdos específicos para este campo, em quaisquer dos eixos de formação (fundamental, profissional e de prática) existentes no art. $5^{\circ}$. Apesar disso, é inquestionável a necessidade/possibilidade de sua inclusão nos três eixos simultaneamente, em razão de imposição normativa sobre a matéria (BRITO, F., 2013).

Não se pode ignorar, outrossim, o art. $8^{\circ}$, da Resolução, que define e caracteriza a atividade complementar, como componentes curriculares enriquecedores e complementadores do perfil do estudante. Por possibilitar o reconhecimento de habilidades, conhecimento e competência do aluno, dentro e fora do ambiente acadêmico, incluiria práticas de estudos e atividades independentes, transversais, opcionais, de interdisciplinaridade, nas relações com o mercado de trabalho e com ações de extensão junto à comunidade (BRASIL, 2004). Assim, ao exigir a inclusão de prática de estudos e práticas transversais e de interdisciplinaridade nas atividades complementares, a resolução estabeleceu, entre outros temas, um evidente liame com os conteúdos ambientais, em especial com a Educação Ambiental (BRITO, F., 2013).

É certo que a inobservância das normas da Educação Ambiental, viabiliza comumente um currículo de graduação vazio de questões ambientalistas, em prejuízo do preparo do corpo discente para o exercício da cidadania ambiental, bem como da formação profissional para a atuação nas áreas jusambientalistas nas mais distintas carreiras jurídicas (advocacia, magistratura, Ministério Público etc.) (BRITO, F., 2013).

Destaca-se que, quando existe - e se é que existe - a preocupação com a inclusão da temática ambiental no currículo de Direito, esta inclusão se restringe, via de regra, à disciplina de Direito Ambiental, que possui um conteúdo específico, restrito e voltado ao universo

Rev. de Direito Ambiental e Socioambientalismo | e-ISSN: 2525-9628 | Maranhão | v. 3 | n. 2 | p. 22 - 41 | Jul/Dez. 2017 
jurídico. Essa disciplina, em razão disso, não supre as exigências normativas para a Educação Ambiental, as suas diretrizes e objetivos, como aqueles previstos na Resolução $\mathrm{CNE} / \mathrm{CP} \mathrm{n}^{\circ}$ 2/2012 ou na Lei nº 9.795/1999 (BRITO, F., 2013).

Por outro lado, o conceito de Direito Ambiental não reconhece como seu objeto de estudo o meio ambiente em si ou a Educação Ambiental propriamente dita, mas, em geral, as normas e os princípios jurídicos, que regulam a relação ser humano-meio ambiente (AMADO, 2009; BELTRÃO, 2009). Desta feita, não pode substituir a inclusão da Educação Ambiental que deve se dar de modo transversal e inter/transdisciplinar - nos Cursos de Graduação em Direito; até mesmo porque são campos distintos do saber. A abordagem pontual e disciplinar da Educação Ambiental (personificada no Direito Ambiental) nos diversos cursos de graduação em Direito em todo Brasil não terá a eficiência almejada, e não permitirá a formação adequada de indivíduos-sujeitos ambientais. Esse cenário é agravado ao considerar-se que os estudantes do ensino superior, por vezes, já ingressam com deficiência nesse conteúdo, vindos de uma educação básica que, da mesma forma, não atende à legislação específica, ao não implementarem a Educação Ambiental (BRITO, F., 2013).

Além disso, ainda que uma única disciplina de Direito Ambiental - a única existente em toda a matriz curricular - pudesse absorver todo o seu conteúdo jurídico específico, em carga horária maior, ainda assim não seria adequado/coerente restringir a ela os conteúdos de Educação Ambiental, que devem interpenetrar-se, de modo transversal e inter/transdisciplinar, em todas as demais disciplinas da matriz curricular. A Educação Ambiental depende dessa perspectiva; porém, é preciso reconhecer-se a dificuldade de implementá-la nos cursos de graduação em Direito, suscetíveis a tendências positivistas, tecnicistas e cartesianas e por uma exigência histórica, mas também contemporânea, de formação prioritária do profissional jurídico para ocupar posição no mercado de trabalho (BRITO, F., 2013).

A resistência, através dos tempos, à adoção de práticas transversais e inter/transdisciplinares no Ensino Jurídico, por parte dos professores, coordenadores e diretores de Cursos de Direito - uma vez que se formaram nesse mesmo contexto -, só agrava o cenário exposto, bem como dificulta a abertura e a integração do Direito com outros campos do saber, a exemplo da Educação Ambiental (BRITO, F., 2013). 


\section{DESAFIOS CONTEMPORÂNEOS A PARTIR DE UM ESTUDO DE CASO}

\subsection{Considerações iniciais}

Para a viabilizar o desenvolvimento deste artigo, partiu-se da análise dos resultados obtidos na pesquisa intitulada "A educação ambiental e a percepção ambiental de alunos e professores do Curso de Graduação em Direito da Faculdade X: um estudo de caso realizado no Sudoeste da Bahia”, cuja a opção metodológica fixou-se em uma pesquisa descritiva, estudo de caso, qualitativa e quantitativa de análise, recorrendo ao: (a) estudo documental e bibliográfico; (b) à observação direta assistemática e sistemática; (c) à aplicação de formulário fechado e aberto a professores e alunos; e (d) à entrevista semiestruturada individual aplicada aos professores e grupo focal aos alunos, sujeitos da pesquisa (BRITO, F., 2013).

A coleta de dados foi realizada na Faculdade X (campo da pesquisa), localizada na região sudoeste da Bahia, e teve como sujeitos alunos e professores do Curso de Direito. A escolha dos professores deu-se de modo não probabilístico, considerando-se aqueles responsáveis por disciplinas da matriz curricular do Curso, durante os semestres 2012.1 e 2012.2. Buscou-se, nesse intento, observar o que diziam/falavam e de que modo tratavam sobre questões ambientais (educação ambiental, direito ambiental, entre outras nomenclaturas e/ou conceitos relacionados). Essa mesma dimensão foi considerada para os alunos do Curso de Direito, do $1^{\mathrm{o}}$ ao $10^{\circ}$ semestre, dos turnos matutino e noturno (BRITO, F., 2013).

A mencionada pesquisa, ainda, efetuou análise documental de documentos institucionais da Faculdade X, a saber: (a) do PPC; (b) Planos de Disciplinas, Currículo e Projetos do Curso; (c) das ementas de disciplinas; (d) plano didático do professor; (e) conteúdos científicos e do cotidiano; e (f) metodologias e avaliação dos conteúdos trabalhados. Isso, com a finalidade de observar como os professores trabalhavam (ou não) com conceitos autônomos, concepções e/ou definições (educação ambiental, cidadania ambiental e meio ambiente), bem como analisar se valorizavam (ou não) a formação do cidadão ambiental, mudanças de atitudes/comportamentos dos seus alunos sobre as questões relacionadas (BRITO, F., 2013).

Rev. de Direito Ambiental e Socioambientalismo | e-ISSN: 2525-9628 | Maranhão | v. 3 | n. 2 | p. 22 - 41 | Jul/Dez. 2017 


\subsection{O estudo de caso propriamente dito e os resultados obtidos}

O estudo de caso analisado permitiu atingir resultados importantes, em face do objeto de estudo, o que envolveu múltiplas dimensões do Curso de Direito da Faculdade X e revelou deficiências na implementação da educação ambiental no ensino jurídico desenvolvido.

A análise dos Planos de Ensino de cada disciplina revelou que, em $60 \%$ dos semestres investigados $\left(1^{\circ}, 2^{\circ}, 3^{\circ}, 4^{\circ}, 6^{\circ}\right.$ e $\left.7^{\circ}\right)$, não houve qualquer referência direta ou, ao menos, indireta aos conteúdos e metodologias exigidas pela legislação específica vigente sobre a educação ambiental. Da mesma forma, que, em toda a matriz curricular, apenas os Planos de Ensino de Direitos Reais ( $5^{\circ}$ semestre), Direito Agrário ( $8^{\circ}$ semestre), Direito Ambiental ( $9^{\circ}$ semestre) e Responsabilidade Civil ( $10^{\circ}$ semestre) versaram direta ou indiretamente - mesmo que de maneira superficial - sobre a temática ambiental. Isso correspondeu a apenas 5,19\% do total de disciplinas de todo o curso de Direito (BRITO, F., 2013).

Além disso, o PPC fez raras menções a aspectos relativos ao campo ambiental e quando as fez não apresentou meios para a instrumentalização da Educação Ambiental no curso de Direito da Faculdade X. A realidade visualizada foi ainda mais grave, quando expostos e analisados os dados obtidos após a aplicação: dos formulários fechados e abertos a professores e alunos; da entrevista semiestruturada, individual, aplicada aos professores; e dos grupos focais realizados com os alunos (sujeitos da pesquisa) (BRITO, F., 2013).

Identificou-se, de regra, o desconhecimento dos sujeitos da pesquisa sobre resoluções do MEC importantes para o Ensino Jurídico e para a Educação Ambiental: (a) Resolução CNE/CES n ${ }^{\circ}$ 09/2004 (Diretrizes Curriculares Nacionais dos Cursos de Direito), desconhecida por $88,15 \%$ dos alunos e por $61,54 \%$ dos professores; e (b) Resolução CNE/CP n $02 / 2012$ (Diretrizes Curriculares Nacionais para a Educação Ambiental), desconhecida por 84,51\% dos alunos e 84,62\% dos professores (BRITO, F., 2013).

A avaliação de conhecimentos dos alunos e dos professores sobre o conceito de Educação Ambiental demonstrou não serem insuficientes, revelando, via de regra, incompreensão de que esse conceito envolve requisitos normativos que regulam, definem e caracterizam a sua prática no ensino formal e não-formal, em todos os níveis, de forma transversal e inter/transdisciplinar. Por outro lado, notou-se que essas respostas afastavam-se consideravelmente dos conceitos doutrinários adotados na pesquisa (BRITO, F., 2013).

Esse desconhecimento ou, ainda, conhecimentos superficiais e incompletos sobre Educação Ambiental ficou, por exemplo, evidente em respostas como: (a) alunos: "Educar meio 
ambiente, = nada" (FA 38), "Não entendo nada, porque não tive ainda a oportunidade de aprender" (FA 110), "Poluição, educação, natureza" (FA 389) e "É o futuro de nossa geração" (FA 405); $\quad$ e (b) professores: "Não tenho opinião" (FP 07) e "Para construir uma nova percepção humana e cultural" (E 01) (BRITO, F., 2013).

79,95\% dos alunos afirmaram que a implementação da Educação Ambiental era importante, mas a maioria não soube justificar porque era, com o fornecimento de respostas como: "O futuro do nosso país depende" (FA 46) (BRITO, F., 2013).

Apenas $7,74 \%$ dos alunos e $23,08 \%$ dos professores afirmaram existirem projetos institucionais sobre o tema sim, o que apontou para uma dificuldade da Faculdade $\mathrm{X}$ de atender prática transversal e inter/transdisciplinar da EA, como exigido pela legislação vigente (BRITO, F., 2013). Outro dado preocupante é que 84,62\% dos professores reconheceram a importância da Educação Ambiental no curso de Direito da Faculdade X, enquanto que 53,85\% a sua importância para a formação profissional. Não obstante isso, 69,23\% disseram não participar de atividade institucional sobre o tema e 61,54\% disseram não incluir a Educação Ambiental no conteúdo das disciplinas que lecionavam, talvez porque $46,54 \%$ dos professores terem afirmado ter dificuldade em ensinar esse tema. Isso pode estar relacionado com a inexistência de capacitação docente para esse fim e para conhecimento das práticas transversais e inter/transdisciplinares; afinal, isso foi afirmado por 100\% dos professores (BRITO, F., 2013).

Acerca do conceito de Cidadania Ambiental, identificou-se um elevado índice de desconhecimento e, por vezes, conhecimentos superficiais e incompletos, a exemplo do observado em respostas como: (a) alunos: "Ser consciente e levar adiante" (FA 131), "O ser age no dia-a-dia (FA 331) ( $8^{\circ}$ semestre), "Serve para todos" (FA 349) (9 $9^{\circ}$ semestre) e "Desconheço este termo" (FA 387) (10 semestre); e (b) professores: "Cuidado com o meio ambiente" (FP 07), "Educação Ambiental" (FP 05), "Uma prática esquecida no Brasil" (FP 03) e "O desenvolvimento de uma conduta compatível com a responsabilidade ambiental" (FP 02). Tanto para alunos como para professores, os conceitos de Cidadania Ambiental fornecidos pelos sujeitos da pesquisa afastaram-se daquele proposto no referencial teórico da pesquisa: o conceito arendt-moriniano (BRITO, F., 2013; BRITO; FERREIRA, 2014).

Apesar de 69,29\% dos alunos afirmarem ser importante a discussão do tema da Cidadania Ambiental no curso de Direito da Faculdade X, a maioria não soube justificar essa importância, o que se observou em respostas como: "Precisamos ajudar" (FA 52), "Não sei o que quer dizer, mas deve ser importante" (FA 72), "Um tema que merece respeito" (FA 182), "Não tenho conhecimento para opinar" (FA 311) (8 semestre), "Preservar é viver (FA 350)" 
( $9^{\circ}$ semestre) e "Desconheço este termo" (FA 387) (10º semestre). Além disso, 55,35\% dos alunos ainda afirmaram que os professores não falavam sobre Cidadania Ambiental em suas aulas, enquanto que apenas 6,38\% afirmaram que falavam (BRITO, F., 2013).

Acerca do conceito de Meio Ambiente, revelou-se um alto nível de desconhecimento e, por vezes, conhecimentos superficiais e incompletos, como observado nas respostas: (a) alunos: "Necessário para o sucesso do homem e para o seu desenvolvimento" (FA 48), "Recursos ambientais" (FA 355), "Meio Ambiente é uma forma de vida na qual temos de preservar, porque está no nosso meio e muitas das vezes somos dependentes dela" (FA 07), "Um conjunto de organismo voltados para a sociedade" (FA 36), "Nada" (FA 38), "O mais importante componente do universo que nos beneficia com seus biomas e riquezas naturais. Proporciona e favorece pra vida saudável de todos" (FA 71), "Um lugar limpo que deve permanecer limpo" (FA 92) e "Meio ambiente é o que gere o ecossistema em que vivemos" (FA 115); e (b) professores: "É a natureza" (E 07), "Valorização dos aspectos relacionados com a qualidade de vida" (FP 11), "A boa convivência entre o ser humano e o ambiente que ele vive" (FP 10), "Preservação da natureza" (FP 05) e "Cuidado com a natureza" (E 08). Nesse cenário, tanto professores como alunos, afastaram-se do conceito de Meio Ambiente adotado na pesquisa (BRITO, F., 2013).

Se 77,22\% dos alunos reconheceram a importância da inclusão do tema Meio Ambiente no Curso de Direito, muitos não forneceram justificativas coerentes para essa resposta: "Não tenho conhecimento para opinar" (FA 311), "O mundo todo não fez o dever de casa e agora a bola da vez é o Brasil, vamos aproveitar esta deixa" (FA 426) (10 semestre), "Regularmente através de disciplina específica" (FA 242) e "Só para os alunos entenderem um pouco sobre o tema, não faz parte do assunto que se estuda em Direito" (FA 03) (BRITO, F., 2013).

Perguntados sobre: (a) de quem seria a responsabilidade pela tutela ambiental, as respostas foram divergentes, por vezes apresentando-se contrárias à CF/1988 (art. 225, caput), que destina essa responsabilidade ao Poder Público e à coletividade; e (b) sobre as práticas pedagógicas adotadas para a inclusão da Educação Ambiental em suas disciplinas, a maior parte dos professores afirmou não incluírem ou incluírem de forma vaga, rara ou superficial (BRITO, F., 2013). 


\section{CONCLUSÃO}

Diante do já exposto, observou-se que a Educação Ambiental e o Ensino Jurídico possuem fundamentos normativos e teóricos diversos. É correto, inclusive, afirmar que surgem em momentos históricos distintos, desenvolvendo-se de modo particular, dentro e fora do Brasil. Isso, no entanto, não as tornam matérias estranhas e incomunicáveis entre si, uma vez que os marcos jurídicos regulatórios de cada uma as conecta, com a finalidade de estimular a formação dos estudantes de Direito, como cidadãos ambientais.

Se a Educação Ambiental deve ser implementada em todos os níveis de ensino, na educação formal e não-formal, em benefício de todos, independentemente de faixa etária (BRASIL, 1981, 1988, 1999, 2012; ONU, 1972, 1975, 1977, 1992), é uma consequência lógica entender-se que se estende a todos os cursos do ensino superior, nos quais se insere o Curso de Graduação em Direito. Não apenas isso, mas que se estende a cada semestre letivo cursado, do $1^{\circ}$ ao $10^{\circ}$, devendo ser ministrada não em uma disciplina específica, mas, de forma transversal e inter/transdisciplinar, em cada uma delas.

É preciso, outrossim, apontar que a Resolução CNE/CES nº 09/2004, que institui as Diretrizes Curriculares Nacionais do Curso de Graduação em Direito, apesar de não mencionar expressamente o termo "Educação Ambiental", estabelece dispositivos que revelam sintonia com o seu conceito e que exigem a sua implementação nas atividades de Ensino Jurídico. Devese, nesse panorama, atentar-se para os elementos estruturais do Projeto Pedagógico do Curso de Direito (PPC), previstos no art. $2^{\circ}, \S 1^{\circ}$ da Resolução, que prevê a necessidade de contextualização da concepção e dos objetivos gerais do Curso e as suas inserções institucional, política, geográfica e social, bem como formas de realização da interdisciplinaridade. Esses os contextos normativos se adéquam às normas vigentes que regulam a Educação Ambiental. Por outro lado, não se pode desconsiderar a exigência de formação geral, humanística e axiológica dos alunos, nos termos do art. $3^{\circ}$, que se agrega com a necessidade de formação do cidadão ambiental.

Em suma, Ensino Jurídico e Educação Ambiental, mesmo tendo regulações específicas e sendo conteúdos distintos, interagem, por predisposição normativa, com a finalidade de otimizar e aprimorar a formação dos estudantes de Direito, contribuindo para as suas formações enquanto cidadãos ambientais.

Por fim, é preciso ressaltar a relevância dos liames existentes entre o Ensino Jurídico e a Educação Ambiental. Em razão disso, confeccionou-se este artigo tendo como referencial a 
pesquisa desenvolvida por Brito (2013), cujos dados coletados e as suas respectivas análises demonstraram os prejuízos educacionais derivados da não implementação das exigências normativas de Educação Ambiental no Curso de Graduação em Direito da Faculdade X. Professores e Alunos apresentando significativo desconhecimento das normas jurídicas específicas sobre a matéria, de noções básicas relacionadas ao campo ambiental (meio ambiente, educação ambiental e cidadania ambiental) e até mesmo do seu papel e do papel do Estado na tutela ambiental.

Apesar do estudo de caso avaliado nesta pesquisa ter coletado dados apenas em um única Instituição de Ensino Superior, a Faculdade X, não se pode descartar que o cenário negativo presenciado não seja a realidade de inúmeras outras. O presente artigo, ademais, reconheceu a gravidade relatada no estudo de caso e o risco de não se associar o Ensino Jurídico e a Educação Ambiental: a formação de pessoas e de profissionais jurídicos insensíveis à causa ambiental e incapazes de atuarem ativamente na defesa e na proteção do meio ambiente ecologicamente equilibrado, como exige o art. 225, caput, da CF/1988.

\section{REFERÊNCIAS}

AMADO, F. A. di T. Direito ambiental sistematizado. São Paulo: Método, 2009.

BELTRÃO, A. F. G. Curso de direito ambiental. São Paulo: Método, 2009.

BRASIL. Lei de 11 de agosto de 1827. Disponível em:

<http://www.planalto.gov.br/ccivil_03/leis/lim/LIM-11-08-1827.htm>. Acesso em: 15 ago. 2017.

Lei no 6.938/1981, 1981. Disponível em:

<http://www.planalto.gov.br/ccivil_03/leis/L6938.htm>. Acesso em: 20 fev. 2012. 2011.

Constituição da República Federativa do Brasil. 1988. Rio de Janeiro: Forense,

Lei no 9.795/1999. 1999. Disponível em:

<http://www.educadoresambientais.com.br/downloads/Lei\%209795.pdf>. Acesso em: 20 fev. 2017.

. Resolução CNE/CES no 9/2004.

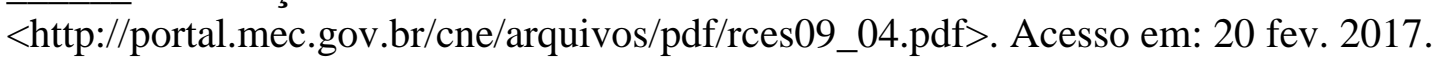

Resolução CNE/CP no 2/2012. 2012. Disponível em:

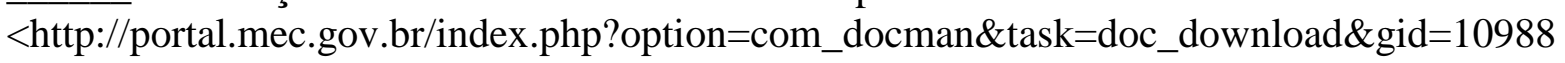
\&Itemid>. Acesso em: 23 set. 2016.

BRITO, Fernando de Azevedo Alves. A percepção ambiental de professores e alunos e a 
educação ambiental no curso de direito da faculdade $x$ : um estudo de caso no sudoeste da Bahia. Itapetinga, BA: UESB, 2013. 282p. (Dissertação - Mestrado em Ciências Ambientais, Área de Concentração em Meio Ambiente e Desenvolvimento).

BRITO, Fernando de Azevedo Alves Brito; BRITO, Álvaro de Azevedo Alves. Recursos hídricos e a educação ambiental: evidenciando liames, tecendo considerações. In: SÉGUIN, Elida; FIGUEIREDO, Guilherme José Purvin de; SOUZA, Luciana Cordeiro de; CARDIA, Regina Helena Picolo (Coord.). Direito Ambiental, Recursos Hídricos e Saneamento: Estudos em comemoração aos 20 anos da Política Nacional de Recursos Hídricos e aos 10 anos da Política Nacional de Saneamento. São Paulo: Letras Jurídicas, 2017.

BRITO, Fernando de Azevedo Alves Brito; BRITO, Álvaro de Azevedo Alves. Recursos hídricos e a educação ambiental: evidenciando liames, tecendo considerações. In: SÉGUIN, Elida; FIGUEIREDO, Guilherme José Purvin de; SOUZA, Luciana Cordeiro de; CARDIA, Regina Helena Picolo (Coord.). Direito Ambiental, Recursos Hídricos e Saneamento: Estudos em comemoração aos 20 anos da Política Nacional de Recursos Hídricos e aos 10 anos da Política Nacional de Saneamento. São Paulo: Letras Jurídicas, 2017.

FORNARI, L. A. P. O ensino jurídico no Brasil e a prática docente: repensando a formação do professor de direito sob uma perspectiva didático-pedagógica. 2007. Disponível em: <http://www.dominiopublico.gov.br/pesquisa/DetalheObraForm.do?select_action =\&co_obra=91396>. Acesso em: 12 ago. 2017.

KOZICKI, K. Afinal, o que significa uma "teoria do direito"? In: CERQUEIRA, D. T. de; FRAGALE FILHO, R. O ensino jurídico em debate: o papel das disciplinas propedêuticas na formação jurídica. Campinas: Milennium, 2007.

LEFF, E. Saber ambiental: sustentabilidade, racionalidade, complexidade, poder. Petrópolis, RJ: Vozes, 2001.

LIMA, G. F. da C. Crise ambiental, educação e cidadania: s desafios da sustentabilidade emancipatória. In: LOUREIRO, C. F. B.; LAYRARGUES, P. P.; CASTRO, R. S. de. Educação ambiental: repensando o espaço da cidadania. 4. ed. São Paulo: Cortez, 2008.

LOUREIRO, C. F. B. Educação ambiental e movimentos sociais na construção da cidadania ecológica planetária. In: LOUREIRO, C. F. B.; LAYRARGUES, P. P.; CASTRO, R. S. de. Educação ambiental: repensando o espaço da cidadania. 4. ed. São Paulo: Cortez, 2008. p. 69-98.

LUZZI, D. Educação ambiental: pedagogia, política e sociedade. In: PHILIPPI JR., A.; PELICIONI, M. C. F. Educação ambiental e sustentabilidade. Barueri: Manole, 2005.

MACHADO, A. A. Ensino jurídico e mudança social. 2. ed. São Paulo: Expressão Popular, 2009.

ONU. Declaração de Estocolmo sobre o ambiente humano, 1972. Disponível em:

<http://www.mp.ba.gov.br/atuacao/ceama/material/legislacoes/declaracao_estocolmo_meio_a mbiente_humano_1972.pdf >. Acesso em: 22 fev. 2012.

Carta de Belgrado, 1975. Disponível em:

<http://www.mma.gov.br/port/sdi/ea/deds/pdfs/crt_belgrado.pdf>. Acesso em: 22 fev. 2012.

Rev. de Direito Ambiental e Socioambientalismo | e-ISSN: 2525-9628 | Maranhão | v. 3 | n. 2 | p. 22 - 41 | Jul/Dez. 2017 
Tratado de educação ambiental, 1977. Disponível em: <http://www.mma.gov.br /port/sdi/ea/deds/pdfs/decltbilisi.pdf>. Acesso em: 22 fev. 2012.

Tratado de educação ambiental para sociedades sustentáveis, 1992. Disponível em: <http://www.ufpa.br/npadc/gpeea/DocsEA/TratadoEA.pdf>. Acesso em: 22 fev. 2012. 